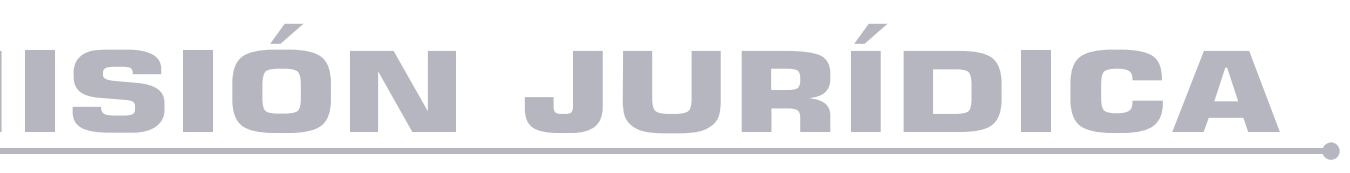

\title{
Los problemas urbanos derivados de la Constitución en México
}

Urban problems as a consequence of the mexican constitution

Autor: Enrique Rabell García

DOI: https://doi.org/10.25058/1794600X.999

\footnotetext{
Ś MISIÓN JURíDICA A
} 


\section{LOS PROBLEMAS URBANOS DERIVADOS DE LA CONSTITUCIÓN EN MÉXICO*} URBAN PROBLEMS AS A CONSEQUENCE OF
THE MEXICAN CONSTITUTION

OS PROBLEMAS URBANOS DERIVADOS DA CONSTITUIÇÃO NO MÉXICO
Enrique Rabell García ${ }^{a}$ erabell@mail.com

Fecha de recepción: agosto 08 de 2018 Fecha de revisión: noviembre 08 de 2018 Fecha de aceptación: diciembre 15 de 2018

\section{RESUMEN}

El desarrollo urbano en México ocasiona problemas de pobreza, dispersión, vivienda, movilidad y mayores costos. Parte de esta problemática proviene del propio texto constitucional que propicia que el orden jurídico y los planes en la materia, otorguen competencias opuestas entre los gobiernos. Como hipótesis se establece que la Constitución y demás normas propician la falta de coordinación ocasionando los problemas citados. El análisis se apoya en la interpretación sistemática y hermenéutica de las normas jurídicas. Se comprueba la existencia de dicha problemática y se Para citar este artículo: Rabell, E.(2019). Los problemas urbanos derivados de la Constitución en México. Revista Misión Jurídica, 12, proponen reformas legislativas y administrativas.

\footnotetext{
* Artículo de investigación científica que presenta resultados de las investigaciones del Cuerpo Colegiado en "Constitucionalismo y Gobierno", UAQ.

a. Profesor e Investigador de Tiempo Completo Universidad Autónoma de Querétaro, México Investigador Nacional, Conacyt.
} 


\section{PALABRAS CLAVE}

$\begin{array}{ccc}\text { Derecho } & \text { Constitucional, } & \text { Derecho } \\ \text { Administrativo, } & \text { Desarrollo } & \text { Urbano, }\end{array}$
Administración Pública y Federalismo.

\begin{abstract}
Urban development in Mexico causes problems like poverty, dispersion, housing, mobility and increased costs. Part of this problem comes from the constitutional text that promotes legal order and urban plans on the matter to provide attributions that are opposed among governments. The hypothesis of this study states that the Constitution and other regulations, triggers a lack of coordination causing the abovementioned problems. The analysis relies on the systematic and hermeneutic interpretation of the entire legal order. The problems are verified and legislative and administrative reforms are proposed.
\end{abstract}

\section{KEY WORDS}

Constitutional Law, Administrative Law, Urban Development, Public Administration, Federalism.

\section{RESUMO}

O desenvolvimento urbano no México causa problemas de pobreza, dispersão, moradia, mobilidade e custos mais altos. Parte desse problema vem do próprio texto constitucional, que permite que a ordem jurídica e os planos na matéria concedam poderes opostos entre os governos. Como hipótese, estabelece-se que a Constituição e outras normas favorecem a falta de coordenação causando os problemas acima mencionados. A análise baseia-se na interpretação sistemática e hermenêutica das normas legais. A existência deste problema é verificada e reformas legislativas e administrativas são propostas.

\section{PALAVRAS-CHAVE}

Direito Constitucional, Direito Administrativo, Desenvolvimento Urbano, Administração Pública e Federalismo.

\section{INTRODUCCIÓN}

Hoy en día se aprecian los múltiples problemas que existen en México en materia urbana. Saltan a la vista cuestiones de movilidad, pobreza urbana, contaminación, vivienda, insuficientes obras de infraestructura urbana, políticas incorrectas en uso de suelo, problemas de abasto de agua, entre otras muchas. Al efecto, existirá una relación entre los incentivos o consecuencias que genera la aplicación del orden jurídico en materia de desarrollo urbano en México frente a dichos problemas. Aunque es claro que las normas correspondientes no son la única variable de estos problemas, se busca analizar si el espíritu de estas, así como los procesos institucionales $\mathrm{y}$ administrativos que nacen de las mismas, son parte esencial de dicha problemática. Así mismo, con dicho análisis se busca vislumbrar posibles soluciones al marco jurídico para generar incentivos positivos y, por ende, mejores políticas públicas en la materia.

De ahí la importancia que tiene el conocer cuáles son las normas principales, los procesos desde la planeación hasta la ejecución, así como los procedimientos y actores institucionales en el desarrollo urbano. En particular destacan los instrumentos de planeación que tienen los tres niveles de gobierno para regular y controlar el desarrollo urbano; así como la capacidad legal y administrativa para su aplicación y seguimiento puntual. Al respecto, se plantea como hipótesis que la Constitución y demás normas tienen competencias incompatibles que propician la falta de coordinación entre los niveles de gobierno, ocasionando los problemas citados.

Se utiliza como técnica jurídica la interpretación sistemática y hermenéutica de las normas jurídicas; y como marco teórico la nueva escuela del institucionalismo para aplicar una visión multidisciplinaria que ayude a tener una panorámica más amplia de esta problemática. Al efecto se utiliza la historia de México, análisis sociales y económicos en materia urbana, así como el estudio de la Constitución y normas vigentes en la materia. Todo ello para desarrollar una interpretación integral y armónica que permita vislumbrar las causas de estos problemas.

Por tanto, los capítulos subsecuentes corresponden en primera instancia a la metodología, comprendiendo los métodos y técnicas de interpretación jurídica aplicados a este estudio; así como la descripción teórica de la nueva escuela de la economía institucional, el cual tiene un enfoque multidisciplinario 
en el estudio de los fenómenos sociales. El capítulo segundo corresponde a la evolución del desarrollo urbano en México principalmente en el siglo XX. El tercero continúa con el siglo vigente, pero ya en una perspectiva de la problemática que se presenta desde lo social y económico. El capítulo cuarto corresponde al análisis de las normas, el cual comprende desde la Constitución, leyes secundarias, problemas jurídico administrativos, así como la jurisprudencia. Finalmente, en las conclusiones se reflexiona en torno a los problemas encontrados en los capítulos anteriores y se presentan una serie de consideraciones para reformar el orden jurídico y, por ende, mejorar las políticas en la materia; además de servir de modelo de interpretación jurídica para los jueces en la materia.

\section{METODOLOGÍA}

\section{Métodos y técnicas jurídicas}

De acuerdo a los fines de esta investigación, se presenta una metodología propia al Derecho y otra relativa a las ciencias sociales que complementa y auxilia las técnicas jurídicas a presentarse. Desde la perspectiva jurídica, las técnicas de interpretación gramatical no son las adecuadas para el presente estudio por sus limitaciones ya que se pretende analizar toda la normativa jurídica en forma simultánea. En este orden de ideas, la interpretación sistemática, "es la que busca extraer del texto de la norma un enunciado cuyo sentido sea acorde con el contenido general del ordenamiento al que pertenece. Procura el significado ateniendo al conjunto de normas o sistema del que forma parte" (Anchondo, 2010, p. 41). Por tanto, tiene la ventaja de permitir un análisis en conjunto de un texto jurídico y así trascender el significado literal.

Sin embargo, dicha técnica sólo considera parámetros o variables estrictamente dentro del texto jurídico y no permite considerar circunstancias sociales, económicas o culturales que estén fuera del texto jurídico y que sin duda se relacionan a éste. De ahí la necesidad de utilizar enfoques más amplios de interpretación como el histórico, genético o teleológico, los cuales abarcan los contextos y circunstancias que influyeron sobre la voluntad del legislador. En este orden de ideas, Arráez et al señalan que la interpretación (o integración) hermenéutica permite incorporar criterios más amplios y vigentes, no sólo los históricos:

De lo que se infiere que el texto una vez que fue escrito adquiere personalidad, asume independencia, y va pasando por el devenir histórico. El texto mismo tiene su contexto, que se ensancha con el paso del tiempo y con las múltiples interpretaciones de que es objeto; por consiguiente, el intérprete debe recibir no sólo el texto en su presencia física, objetiva, sino con los variados comentarios que se han hecho de él. Por consiguiente, puede el intérprete criticar, argumentar, captar en una totalidad las diferentes partes del texto, ubicándolos en el amplio contexto social; utilizar los procedimientos dialécticos que amplíen los significados captados con anterioridad, pues toda interpretación implica innovación y creatividad en la medida en que la interpretación del texto o de la acción humana enriquezca su descripción o comprensión (Martínez, 1999). (Arraez et al, 2006: 180).

De ahí la importancia del método o técnica hermenéutica para poder considerar todas las normas jurídicas en conjunto que afectan la problemática urbana en estudio. Sin embargo, aunque la visión hermenéutica ya utiliza otras ciencias para auxiliarse en sus reflexiones; es imprescindible saltar de una visión jurídica de los problemas a un enfoque diferente en las ciencias sociales en razón de la complejidad propia de los problemas urbanos que son multidisciplinarios. En consecuencia, la perspectiva metodológica de la nueva economía institucional representa la mejor herramienta para complementar las técnicas jurídicas y así incrementar el análisis y conclusiones en forma armónica.

\section{Marco teórico, la nueva economía institucional}

Mediante la nueva economía institucional se busca acreditar la relación entre los incentivos o efectos que generan las normas jurídicas al momento de su aplicación frente a los problemas existentes en materia de urbanismo. La visión de la nueva corriente del institucionalismo y, en particular, la "Nueva Economía Institucional" (NEI), permiten complementar la interpretación 
de las normas al brindar información sobre la estructura y funcionamiento de las instituciones, los incentivos que se crean, las reglas y tratos entre los actores que intervienen, así como una serie de características (por ejemplo, los derechos de propiedad y costos de transacción), que influyen en las conductas de las personas, así como su forma administrativa de aplicar las leyes.

North (1990, pp. 3-5) señala que las acciones humanas se encuadran dentro del marco institucional y ofrecen una estructura para la vida diaria con la doble finalidad de reducir la incertidumbre, al mismo tiempo que limitan las alternativas de los individuos; en pocas palabras, las instituciones surgen para dar seguridad y facilitar la vida al reducir las alternativas en la toma de decisiones. Por su parte Crawford y Ostrom (1995, p. 582) señalan que las instituciones son "regularidades duraderas de la acción humana, estructuradas por reglas, normas y estrategias compartidas, así como por el medio físico. Las reglas, normas $\mathrm{y}$ estrategias compartidas son constituidas $\mathrm{y}$ reconstituidas por la interacción humana en situaciones repetitivas."

En particular el institucionalismo busca encontrar todas aquellas características y rasgos que expliquen el éxito o fracaso de todo tipo de instituciones, sean formales o no. Carrasco y Castaño (2012, p. 43) son partidarios utilizar varias disciplinas con un enfoque institucional; considerando que:

(...) la finalidad de la NEI es explicar la importancia de las instituciones en la vida social, utilizando el lenguaje económico, pero integrando conceptos de disciplinas como el derecho, la ciencia política, la sociología, la historia, o la antropología. Autores destacados y precursores de la NEI son los cuatro galardonados con el Premio Nobel de Economía: Ronald Coase (1991), Douglas North (1993), Oliver Williamson (2009) y Elinor Ostrom (2009).

De esta forma, los estudios aplicados al urbanismo en México, derivados del enfoque del nuevo institucionalismo, deben brindar información valiosa que permita conocer los efectos de la aplicación de las normas urbanas en los tres niveles de gobierno.

\section{ANTECEDENTES DEL URBANISMO EN MÉXICO}

\subsection{Los inicios del urbanismo en el siglo XX}

Se pretende presentar un muy breve repaso sobre los antecedentes urbanos en México, como un referente de la forma en que se ha desarrollado esta temática. Es así que durante el Porfiriato inicia la expansión urbana con nuevos fraccionamientos y colonias en la Ciudad de México (por ejemplo, las colonias Roma, Condesa, Coyoacán); la consolidación de ciudades importantes en el centro y el norte como Querétaro, Puebla, Monterrey o Chihuahua; así como la ampliación de centros de población como León, Tijuana, Tampico y Tuxtla Gutiérrez entre otros (Cárdenas, 2012, p. 30). En este período se utilizaron los esquemas adoptados del urbanismo francés y estadounidense, derivados de la ideología del gobierno para tener mayor modernidad, así como competitividad comercial e industrial. Se dio un gran dinamismo de construcción y múltiples inversiones del sector capitalista; la población se incrementó y surgió la especulación por el uso y destino del suelo; las haciendas, ranchos, molinos y potreros cercanos a la capital mexicana e incluso tierras comunales y ejidales se vendieron para construir solares y fracciones de terreno destinados a la vivienda residencial del nuevo estilo burgués de aquellos años.

Se puede señalar que la planeación urbana, como tal, quedó detenida durante la Revolución mexicana hasta lo que podríamos llamar la pacificación institucional durante la presidencia de Lázaro Cárdenas (1934 - 1940). De esta forma en esta primera etapa se verifica el inicio de la migración masiva del campo a las ciudades, así como el inicio de la planeación mediante los Planes Quinquenales impulsados en el sexenio de Cárdenas.

Ya para el período de 1950 a 1970 se experimenta un intenso crecimiento demográfico (de 30 millones a 50 millones de habitantes aproximadamente) y económico. Inicia la verticalidad y reciclamiento en la edificación urbana, así como una mayor expansión urbana y aparición masiva de los suburbios (particularmente el Valle de México). En esta época surgen, entre el sector público y privado, 
los primeros "Planos Reguladores" en materia de desarrollo urbano a un nivel sub sectorial (Cárdenas, 2012, p. 36).

Destaca, al inicio de los setentas, la creación de la Subsecretaría de Bienes Inmuebles y Urbanismo, como la primera instancia federal para regular este tema. Se elabora una metodología oficial para desarrollar estudios y planes en este ámbito. Se realiza el primer estudio nacional de desarrollo urbano, del cual se desprenden planes municipales y otros de desarrollo urbano por parte del sector privado.

Como ejemplo de esta etapa se concibe al municipio de Cuautitlán Izcalli usando como base los planos de ciudades europeas y estadounidenses (Edward Basset impulsó el zoning en New York desde 1910), para transformar los terrenos en áreas apropiadas para el establecimiento de centros de trabajo, de servicio y de habitación con la idea de contar con áreas deportivas e industriales, zonas residenciales y áreas verdes; ejemplo que se desarrolló en varias ciudades más.

\subsection{La expansión urbana}

Del período de 1976 a 1990 se da la transformación definitiva de un entorno rural a uno urbano mayoritariamente concentrado en centros de población. Aparecen ciudades conurbadas con sus problemáticas (Valle de México, Guadalajara, Monterrey principalmente). Se promulgó la Ley General de Asentamientos Humanos, la cual es rectora de toda la planeación urbana; y como consecuencia la creación de instancias formales para regular la Ley, como la Subsecretaría de Desarrollo Urbano adscrita a la Secretaría de Asentamientos Humanos y Obras Públicas de ese entonces. Se crean también las comisiones para la planeación de las zonas metropolitanas. Así mismo, aparecen los planes de desarrollo en los tres niveles de gobierno (por ejemplo: en los ochentas se hacen los primeros planes parciales de desarrollo urbano de las delegaciones del Municipio de Querétaro). Además, se promulgó el primer Plan Nacional de Desarrollo Urbano en 1978. Destaca también por su injerencia en el tema la promulgación de la Ley General de Equilibrio Ecológico y Protección al Ambiente.

Gutiérrez (2009, p. 61) opina que no obstante el impulso ya anotado a la planeación urbana, la preeminencia que se dio al Sistema Nacional de Planeación Democrática de mediados de los ochentas, cambió como eje principal del Gobierno federal la cuestión económica, desplazando con ello a la cuestión urbana. Señala, además, que en lugar de que en los noventas los asuntos urbanos recuperarán un importante papel en las políticas públicas, la cuestión social junto con la económica serán las principales, "con el impulso de programas como el de "Ciudades Medias" y el de "100 Ciudades" en los cuales la planeación urbana asume un carácter secundario limitado a la regulación del crecimiento de las ciudades desde una perspectiva espacial carente de una visión integral y sin mostrar signos de avance."

En la última década del siglo anterior continua el crecimiento demográfico al alcanzarse los 100 millones de habitantes, $70 \%$ de ellos en centros urbanos de las ciudades importantes, así como en ciudades fronterizas. A pesar de la ya existencia de instrumentos legales y planes en la materia, la caracteriza principal es el incremento de la construcción incontrolada de infinidad de conjuntos habitacionales, urbanos y mayoritariamente de carácter popular o interés social, ubicados en forma adyacente a los centros de población, ocasionando infinidad de problemáticas por la gran dispersión urbana.

\section{PROBLEMÁTICA ACTUAL}

\subsection{Aspectos socio económicos}

La situación actual se abordará desde una perspectiva socio económica e institucional, señalando los problemas demográficos, de dispersión, vivienda, movilidad y costos públicos.

En lo relativo a lo social, la problemática es notoria desde una primera visión demográfica. Según el Consejo Nacional de Población (CONAPO, 2007) el 77\% de la población (alrededor de 86 millones) en México es urbana y se calcula que para el 2030 la proporción subirá a un 81\%. Además, el Centro de Investigación de la Casa (CIDOC, 2012) señala que las urbes en México generan el $86.5 \%$ del PIB. Sin embargo, dichas ciudades son responsables de la concentración de la pobreza y desigualdad social según la Secretaría de Desarrollo Social (SEDESOL, 2009, p.3), ya que alrededor del $40 \%$ de la población urbana vive en condiciones de pobreza. Los más pobres están obligados a vivir en la periferia urbana o zonas de riesgo, carecen de acceso a los servicios básicos y, 
en su mayoría, en condiciones de irregularidad de la propiedad de la tierra que ocupan.

El crecimiento de la población, así como de las zonas urbanas, no implica por sí mismo una carga negativa, ya que es posible que se dé en forma ordenada. El problema central consiste en la dispersión de la ciudad, la cual genera múltiples problemas. Por lo cual resulta importante justificar su existencia. Como primer análisis se compara el crecimiento de la población frente a la mancha o área urbana contenido en el análisis de planes de movilidad del Instituto de Políticas para el Transporte y el Desarrollo (ITDP, 2012, p. 17). Al considerar el período de 1980 al 2010 tenemos como ejemplos que: en Querétaro creció la población $9.3 \%$ y el área urbana un 14\%; en Puebla la población $4.5 \%$ y el área $13.4 \%$; la Laguna $2.9 \%$ frente a $11 \%$ del área; en León un $4 \%$ y la mancha un $10.1 \%$; Juárez la población un 4.4\% frente a 9.6\%; Monterrey 3.5\% comparado a 8.3\%; Guadalajara 3.5\% frente a 6.9\%; y el Valle de México un $1.8 \%$ frente a un área urbana de $6.6 \%$.

Esta muestra de ciudades confirma que ha existido una gran dispersión al permitir desarrollos inmobiliarios y demás obras en las periferias de las ciudades, lo que ocasiona que crezca más rápido la mancha urbana que la población, creando con ello un sinnúmero de problemas. Problemas que inclusive son reconocidos en forma oficial en el Programa Nacional de Desarrollo Urbano 2014-2018, el cual señala en forma puntual:

Un segundo efecto del proceso de urbanización en México es la expansión desproporcionada de la mancha urbana. En las ciudades mexicanas el crecimiento del territorio urbano no siempre ha respondido a la tendencia del crecimiento poblacional. Así, mientras la población urbana se duplicó durante los últimos treinta años, la superficie urbana se multiplicó por seis (Programa Nacional de Desarrollo Urbano 2014-2018, 30 de abril del 2014).

\subsection{Ineficiencia institucional}

Siguiendo el mismo Plan citado arriba, se específica que otras de las consecuencias del proceso de expansión desordenado de las ciudades fue la política de vivienda. Al efecto, señala que el modelo de atención a las necesidades habitacionales privilegió el otorgamiento masivo de financiamiento para vivienda nueva sin considerar su impacto territorial, urbano y ambiental al tiempo que la industria desarrolladora encontró una oportunidad de negocio en la producción de vivienda de interés social en lugares donde el suelo era más barato, lugares cada vez más alejados de los centros urbanos consolidados.

En el mismo sentido el Instituto Mexicano para la Competitividad (IMCO, 2011, p. 15) señala que el actual modelo de crecimiento urbano ha sido determinado por el mercado inmobiliario, siendo disperso, desordenado, con bajas densidades, sin usos de suelo mixto e insustentable. La construcción masiva de vivienda se ha disparado ocasionando dicha problemática. Por ejemplo, el Instituto Nacional de Vivienda (INFONAVIT) otorgó poco más de 3.2 millones de créditos más que en comparación con los 30 años anteriores. Además, el propio INFONAVIT (2010, p. 32) cita que para el 2010 , el $26 \%$ de las viviendas financiadas por esta vía se encontraban desocupadas o abandonadas; siendo el $21 \%$ de los casos el resultado de la distancia que separa las viviendas de la ciudad.

El Programa Nacional de Desarrollo Urbano ya citado, señala además que un efecto adicional de esta política de vivienda, "fue el reforzamiento del patrón de urbanización periférica de baja densidad con usos predominantemente habitacionales, modelo que hasta el día de hoy tiene importantes efectos negativos en la cohesión social, la economía y la conectividad de las ciudades."

Respecto de la movilidad, el ITDP encontró problemas relacionados entre la dispersión y la movilidad; puntualizando al efecto:

(...) la actual política de vivienda ha fragmentado el espacio urbano, aumentado las distancias y tiempos de traslado y ha puesto en jaque la estructura territorial y ambiental de las ciudades mexicanas. Un patrón de desarrollo disperso, de baja densidad y sin usos de suelo mixtos, obliga a los ciudadanos a vivir menos la ciudad, a recorrer distancias más largas, a utilizar el automóvil y a caminar menos. Este patrón de desarrollo urbano hace costoso y difícil establecer sistemas de transporte público, trasladarse en bicicleta o 
caminar. La lejanía también obliga a consumir una mayor cantidad de energía para el transporte y a destinar espacio público para vialidades (2012: 17).

De tal forma que la dispersión genera servicios de transporte públicos ineficientes (las soluciones de transporte como trenes elevados, subterráneos y similares, requieren mayores densidades de población), además de hacer inútiles las soluciones para privilegiar las bicicletas o caminar; contando con el aumento exponencial del tráfico vehicular y contaminación respectiva. El Programa Urbano aludido reporta los problemas derivados para llegar a los trabajos, generando costos muy altos en dinero y tiempo.

El $15 \%$ de los hogares en zonas urbanas reporta que gasta aproximadamente entre 51 y 200 pesos diarios para trasladarse de su casa al trabajo. En el Valle de México, el porcentaje de hogares que paga dicha cantidad aumenta a 16\% y en las ciudades de más de un millón de habitantes aumenta a $21 \%$. En cuanto al tiempo de traslado se refiere un $62 \%$ de los hogares encuestados reportan que a la persona que más aporta al gasto familiar le toma entre 23 y 38 minutos llegar a su centro de trabajo (Programa Nacional de Desarrollo Urbano 2014-2018, 30 de abril del 2014).

Respecto de los costos, el Programa menciona que además de los incluidos a los ciudadanos de movilidad y derivados de la distancia, se incluyen los públicos. El modelo de ciudad extendida genera mayores costos en la provisión de servicios básicos por parte del gobierno, aunado a la debilidad financiera de las recaudaciones locales, se traduce en desigualdades en la calidad y oportunidad con la que los gobiernos locales proveen bienes públicos a los ciudadanos. El costo de introducción de servicios públicos, una vez que se han consolidado los asentamientos humanos que no fueron planeados, es 2.7 veces mayor. La provisión de servicios básicos como estrategia para conectar desarrollos alejados de las ciudades, sumando al abandono de los centros de las ciudades debido al deterioro de inmuebles provoca subutilización del equipamiento e infraestructura e incluso genera incentivos para la especulación del suelo. De esta forma se aprecia la razón por la cual muchas políticas a nivel local (ciclo vías, tráfico, obras públicas, seguridad pública, medio ambiente, etc.) no podrán tener un impacto significativo en tanto no exista una política urbana principal que busque compactar la ciudad.

\section{MARCO CONSTITUCIONAL Y JURÍDICO}

\subsection{La Constitución}

En primer plano los artículos $25^{\circ}$ y $26^{\circ}$ de la Constitución Política de la República de 1917 establecen el sistema de planeación democrática para el gobierno. Esto es, cada nivel de gobierno tendrá su plan general de gobierno en cada inicio de sus administraciones (cada seis años en lo federal y estatal y 3 a nivel municipal). Además, el artículo $27^{\circ}$ establece las modalidades públicas de la propiedad e intervención en la privada, las cuales corresponden también a todos los niveles de gobierno; así como el régimen de la propiedad pública estatal de los recursos naturales, dominio que corresponde al orden Federal.

En particular la materia urbana presenta competencias no tan claras, ya que el artículo 73 , fracción XXIX-C constitucional, establece en forma puntual la concurrencia de los tres niveles de gobierno en materia de "Asentamientos Humanos". Lo cual le da a la Federación una preeminencia en esta materia (ya que compete a la Federación legislar en forma inicial) y, en forma indirecta, lo relativo al desarrollo urbano por medio de esta competencia (Reformado: DOF, 6 de febrero de 1976). Este mismo esquema se repite en relación con la materia de protección al ambiente y preservación y restauración del equilibrio ecológico en términos de concurrencia. Materias que son esenciales en el concepto de desarrollo urbano sustentable (Reformado: DOF, 10 de agosto de 1987).

Sin embargo, además de la concurrencia ya citada, el artículo $115^{\circ}$ constitucional establece competencias específicas para los municipios. En particular la fracción $\mathrm{V}$ establece las competencias para formular y administrar la zonificación y planes de desarrollo urbano municipal; crear y administrar sus reservas territoriales; formular planes de desarrollo regional en concordancia con los de la Federación y Estado; autorizar, controlar y vigilar la utilización del suelo; intervenir en la regularización de la tenencia de la tierra urbana; otorgar licencias y permisos para construcciones; participar en la creación y administración de 
zonas de reservas ecológicas y en la elaboración y aplicación de programas de ordenamiento en esta materia; intervenir en la formulación y aplicación de programas de transporte público de pasajeros; celebrar convenios para la administración y custodia de las zonas federales (Reformada: DOF, 23 de diciembre de 1999); y, fracción VI, cuando dos o más centros urbanos situados en territorios municipales de dos o más entidades federativas formen o tiendan a formar una continuidad demográfica, la Federación, las entidades federativas y los municipios respectivos, en el ámbito de sus competencias, planearan y regularan de manera conjunta y coordinada el desarrollo de dichos centros con apego a la ley federal de la materia (Reformada: DOF, 3 de febrero de 1983).

Por tanto, se puede apreciar una primera complejidad ya que por un lado existe la concurrencia en materia de Asentamientos Humanos y Ecología, lo cual es aplicable al desarrollo urbano; y por otra parte existen competencias "únicas" para los municipios en materia de desarrollo urbano; creando al efecto una serie de conflictos al interpretar y aplicar estos principios constitucionales.

\subsection{La legislación secundaria}

Esta situación se aprecia con claridad en el contenido de la normativa federal relativa a la Ley General de Asentamientos Humanos (2016), la cual parece que confirma la preeminencia del orden Federal. Destacan las siguientes atribuciones conferidas a la Secretaría de Desarrollo Agrario, Territorial y Urbano federal: coordinar la planeación del desarrollo regional; prever a nivel nacional reservas territoriales para el desarrollo urbano; formular y ejecutar el programa nacional de desarrollo urbano; así como participar en la ordenación y regulación de zonas conurbadas, entre otras.

Mediante el capítulo III, el orden federal tiene bajo su responsabilidad, por medio del Sistema Nacional de Planeación Democrática, el programa nacional de desarrollo urbano, el cual es el eje rector en la materia para los tres órdenes de gobierno. El capítulo cuarto otorga responsabilidades de trascendencia para las situaciones de conurbación o ciudades metropolitanas, esto es, cuando una ciudad se junta con otra, o sobrepasa sus límites entre municipios. Inclusive su existencia jurídica depende de un decreto federal que tiene que ser publicado en el Diario Oficial de la Federación.

El capítulo quinto relativo a la regulación de la propiedad en los centros de población otorga competencias a los estados y municipios. Por ejemplo, la fundación de los centros de población deberá expedirse por las legislaturas estatales; los planes y programas municipales de desarrollo urbano deberán prever la conservación, mejoramiento y crecimiento de los centros de población; los requisitos que debe contener la legislación estatal en materia de desarrollo urbano o las políticas de zonificación de acuerdo con esta Norma federal; todas estas competencias supeditadas a los programas y políticas nacionales en la materia.

El capítulo sexto prevé la coordinación en materia de reservas territoriales. El séptimo los mecanismos de participación social para los tres niveles de gobierno. El octavo que habla sobre fomento al desarrollo urbano establece incentivos por los cuales la Federación podrá conducir políticas como instrumentos financieros y fiscales, protección del patrimonio cultural; modernización de los sistemas catastrales y registrales, o aplicación de tecnologías en la materia, entre otras. Por último, el capítulo noveno sobre control de desarrollo urbano establece como uno de sus mecanismos la disposición de que no surtirán efectos los actos, convenios y similares relativos a la propiedad o cualquier otro derecho relacionado con el aprovechamiento de áreas y predios que contravenga esta ley, la legislación estatal en la materia y los planes o programas de desarrollo urbano. Por tanto, resulta clara la superioridad de la ley federal frente a la legislación estatal y municipal en esta materia; así como sus actos administrativos.

En el ámbito estatal existe en principio la subordinación a la ley anterior. Al tomar el Estado de Querétaro como ejemplo (lo cual se repite en este orden tanto por mandato Constitucional como por las prácticas centralistas), aunque existen varias disposiciones en la materia (por ejemplo: las leyes respectivas a la Protección del Ambiente y sobre la Planeación democrática; Ley para la Regularización de los Asentamientos Humanos Irregulares, entre otras), el principal instrumento consiste en el Código Urbano, el cual entró en vigor en junio de 2012. Siguiendo la normativa federal, 
destaca en el título primero la concurrencia entre el Estado y sus municipios, así como las competencias de las autoridades en materia inmobiliaria, desarrollo urbano, construcción, agua, caminos, carreteras, entre otras.

El título segundo versa sobre la planeación urbana, ordenación y regulación territorial, así como asentamientos humanos. En este destaca el Sistema Estatal de Planeación Urbana, el cual tiene por una de sus finalidades la expedición de los programas Estatal de Desarrollo Urbano, Subregionales de Desarrollo Urbano, Ordenación de zonas metropolitanas; municipales de Desarrollo Urbano, Desarrollo Urbano de Centros de Población, y parciales de Desarrollo Urbano (por ejemplo, a nivel de las delegaciones de los municipios). Es importante recalcar que su importancia y jerarquía van del primero al último citado, por tanto, los programas inferiores no podrán contravenir disposiciones de los superiores. Estos programas tendrán que tener un horizonte no menor a 10 años. Destaca al finalizar el presente título la creación de la Procuraduría Estatal de Protección al Medio Ambiente y Desarrollo Urbano (sección segunda); la Acción Popular (sección tercera); y los observatorios urbanos (sección cuarta); como instrumentos para afianzar las políticas públicas en la materia.

El título tercero se avoca a la regulación de los desarrollos inmobiliarios, el cual es esencial para regular la urbanización y tipos de vivienda. El título cuarto que establece las reglas principales para la construcción en terrenos y edificaciones públicos y privados, así como sus modalidades. El quinto relativo a las obras de urbanización mediante el sistema de obras por cooperación y captación; como un importante complemento al desarrollo urbano. El título sexto sobre el agua potable, alcantarillado y saneamiento, el cual incluye la creación de la Comisión Estatal de Aguas. El título séptimo sobre carreteras, caminos y otras vialidades, creándose al efecto la Comisión Estatal de Caminos del Estado. Y el título octavo sobre cuestiones administrativas generales al Código.

A nivel municipal en el Estado de Querétaro, se encuentran la Ley Orgánica Municipal de 2001; y, en el caso del Municipio de Querétaro, se encuentra el Código Municipal de 2004, destacando dentro de su título primero el Apartado Tercero sobre las atribuciones del municipio en materia de Desarrollo Urbano; así como los reglamentos en materia Ambiental; de Construcción; y de Parques, Jardines y Áreas Verdes, entre otros.

\subsection{Los planes urbanos}

Derivados de las normas ya citadas, los principales instrumentos para ordenar el desarrollo urbano consisten en los planes en la materia. En atención a la Ley General de Asentamientos Humanos el plan de mayor jerarquía es el Programa Nacional de Desarrollo Urbano, pudiendo derivar de éste planes particulares por materia (movilidad, pluviales, económicos, etc.) o geográficos cuando abarquen dos o más estados, llamados regionales o metropolitanos si involucra manchas urbanas interestatales. En este orden de jerarquía le siguen los planes estatales en la materia, de los cuales pueden derivarse por materia o regionales si involucran a dos o más municipios.

En el nivel municipal y siguiendo los planes arriba citados; así como las normas propias del municipio, se agregan los planes municipales de desarrollo, los cuales tienen una vigencia de tres años; así como los planes de desarrollo urbano municipal y parcial para las delegaciones en los casos correspondientes, como instrumentos fundamentales de planeación y políticas públicas urbanas de mediano y largo plazo.

\subsection{Los conflictos jurídicos}

Aunque parece un orden jerárquico y lógico en la normativa revisada, se encuentran los siguientes problemas de la revisión de las normas en cuestión: la autoridad federal no tiene una competencia clara o directa para regular cuestiones municipales de urbanismo por medio de las competencias en materia de asentamientos humanos; existe una gran dispersión en la materia de desarrollo urbano al existir normativa en muchas materias relacionadas (medio ambiente, agua, protección civil, reglamentos de imagen urbana, usos de suelo agrícolas y forestales, vías de comunicación, etc.), lo cual crea una gran complejidad jurídica y administrativa; debido a los ciclos de gobierno, los planes estatales y municipales siempre están desfasados del Federal; el municipio con fundamento el 115 constitucional nacional y sus propios reglamentos, por medio del ayuntamiento tiene la capacidad jurídica para tomar decisiones unilaterales que 
puedan ir en contra de las normas y planes federales y estatales en la materia (ejemplo de ello se aprecia en materia metropolitana, cambios de uso de suelo en contra de zonas estatales o federales con otra vocación, crecimiento de la mancha urbana, entre otros).

Desde una perspectiva legal y administrativa, el ITDP (2012, pp. 22-23) en referencia a los planes de desarrollo urbano encontró que: $60 \%$ de los documentos tienen la intención de aplicar un enfoque integral, sin embargo sólo el $40 \%$ se acerca a una visión sustentable de movilidad; ningún documento considera la gestión de movilidad; se justifican grandes inversiones en infraestructura pero se da muy poca importancia a la búsqueda de soluciones que afecten menos al medio ambiente, tales como reducción de energéticos; un 53\% considera la movilidad ciclista; sólo una tercera parte hace propuestas en referencia a la movilidad peatonal; no existe claridad en las dependencias responsables de la aplicación de los planes integrales de movilidad urbana, por lo que sus planes son susceptibles a los cambios políticos y administrativos (salvo Monterrey y Distrito Federal); sólo cuatro documentos incluye la participación social; debido a que la Ley y el Sistema de Planeación no tiene claridad en cuanto al PIMUS, cada ciudad ha realizado un ejercicio distinto, lo cual hace imposible un sistema nacional de información y realizar comparaciones.

Esta conflictiva jurídica también se acreditó al realizar una serie de entrevistas aplicadas a funcionarios de los tres niveles de gobierno, con motivo de las reuniones anuales que realiza la Secretaría de Desarrollo Sustentable y Territorial federal; siendo en esta ocasión la "Reunión de Trabajo del Panel de Alto Nivel de la Organización de las Naciones Unidas (ONU), que evaluará a ONU-Hábitat en México, efectuada en mayo del 2017. Al efecto se pudieron realizar 15 entrevistas, aplicadas a servidores de la Secretaría ya citada (3), de nivel estatal de secretarías de desarrollo económico y obras públicas (6 diferentes estados); y a nivel municipal en secretarias afines (6 diferentes municipios). Si bien la muestra no es representativa desde la disciplina estadística, si permite vislumbrar una tendencia importante, en virtud de la homogenización del orden jurídico, vía la concurrencia en la materia contenida en el artículo 73 de la Constitución federal y
Ley General de Asentamientos Humanos, así como la reglamentación municipal derivada del artículo 115 constitucional. Las entrevistas fueron abiertas (ver guía en anexo I), siendo los principales resultados:

a) Los servidores públicos federales no cuentan con instrumentos o instancias legales para hacer cumplir los planes y programas federales a nivel estatal y municipal; las controversias constitucionales o inconstitucionalidad de leyes es muy raro que se promuevan y no ayudan a resolver los problemas de coordinación.

b) A nivel estatal todos destacaron que, en la elaboración de leyes y planes, si se acatan las leyes y planes federales correspondientes, y que existe colaboración con dichas autoridades para su elaboración. Sin embargo, para su aplicación y seguimiento, aunque si existen reuniones con los otros niveles de gobierno, ellos cuentan con la competencia para hacerlo en forma unilateral.

c) En el ámbito estatal, en muy pocas ocasiones existe un litigio formal frente a la Federación, a nivel municipal, en cambio, este es más frecuentes. Los conflictos jurídicos más comunes con la Federación corresponden a la interpretación de las competencias concurrentes (asentamientos, medio ambiente, movilidad, etc.), lo que ocasiona la complejidad para elaborar los planes y la gran dificultad para hacer planes conjuntos con la Federación o los regionales con otras entidades; además de la forma para efectuar la evaluación, especialmente con organismos descentralizados (ejemplo Comisión Nacional del Agua, Procuraduría del Medio Ambiente federal, etc.). Esto ocasiona que las políticas en urbanismo sean lentas y vayan siempre rezagadas.

d) Los funcionarios estatales consideran que tienen preeminencia sobre las políticas municipales. Sin embargo, no dudaron en señalar que la conflictiva con los municipios es mucho mayor, ya que se reproducen los anteriores problemas en materia de concurrencia, además de las competencias derivadas del artículo 115 constitucional, que utilizan dichos funcionarios para fundamentar sus actuaciones. Así, denotaron también la falta de instrumentos agiles para hacer valer los planes y programas estatales frente a los municipios. 
e) En el ámbito local se aprecia que los municipios con mayor capacidad técnica sí toman en cuenta la normativa y planes desde lo Federal a lo estatal, en la elaboración de sus propias políticas. Sin embargo, todos coincidieron que el ayuntamiento (órgano máximo de gobierno del municipio) tiene la competencia directa para realizar cualquier modificación, no sólo a dicha normativa superior, sino inclusive a sus propios planes y programas en la materia, con el fundamento que otorga el artículo 115 constitucional. Señalando además que es frecuente que en cada sesión de cabildo se den modificaciones.

f) Todos citaron que es un reto poder contar con una política urbana en forma coordinada, ya que no sólo está la complejidad de los tres niveles de gobierno, sino que también en el propio nivel existen otras secretarías y entidades que tienen competencias en la materia.

\subsection{La actividad de la Corte}

La conflictiva jurídica llega hasta la propia Suprema Corte de Justicia de la Nación, ya sea vía amparo de los particulares (muy común para obtener permisos en áreas no convenientes), o vía controversia constitucional entre autoridades de diferentes niveles. Apreciándose tanto en el buscador de la Corte, así como en otros, la gran cantidad de actividad judicial en esta materia. Al respecto y con objeto de citar algunos casos representativos, la controversia constitucional 94/2009 entre el Municipio de San Pedro Garza García en contra del Estado de Nuevo León, consideró al valorar los artículos $73^{\circ}$ fracción XXIX-C y 115 de la Constitución, en el numeral Séptimo:

Pues bien, ni de la redacción de la fracción $\mathrm{V}$ del artículo 115, ni de los orígenes de la facultad concurrente en materia de asentamientos humanos, se desprende que el Municipio tenga una facultad exclusiva y definitiva en la materia de desarrollo urbano. Los casos de la fracción $\mathrm{V}$ del artículo constitucional citado deben entenderse en el contexto de las facultades concurrentes distribuidas constitucional y legalmente, y que deben ser desarrolladas: "en los términos de las leyes federales y estatales relativas (Sentencia de Controversia Constitucional 94/2009, julio de 2011).
De dicha redacción y considerando que la reforma constitucional al artículo $73^{\circ}$ fracción XXIX-C, que establece la concurrencia en la materia, fue anterior a la reforma al artículo $115^{\circ}$ en materia de desarrollo urbano, se concluyó la jerarquía de la regla de la concurrencia (y por ende de la legislación federal), por encima de supuestas facultades "únicas" de los municipios, con lo cual se negaron las pretensiones de dicho Municipio de hacer valer facultades exclusivas en su favor.

En un sentido similar se pronunciaron dos sentencias en contra del Instituto de Vivienda del Estado de Quintana Roo por dos municipios diferentes (SCJN, 2013, p. 173). Sin embargo, aunque es anterior a las otras, la controversia en contra de la Ley de Asentamientos Humanos y Desarrollo Urbano para el Estado de Nayarit, encontró la legalidad de ciertos artículos de dicho Ordenamiento, así como la ilegalidad de otros, con lo cual reconoció que el municipio sí cuenta con ciertas facultades exclusivas o propias en materia de desarrollo urbano. Y así como estos ejemplos hay suficientes que muestran la diversidad de opiniones de la Corte. Por lo que se aprecia que tampoco existe un criterio uniforme en el más alto Tribunal del País, acreditándose la gran complejidad en la materia y repercusiones que esto tiene.

Si bien la jurisprudencia de la Corte tiene la finalidad de interpretar, integrar o resolver estos casos conforme se vayan presentando, la enorme cantidad de problemas jurídicos y administrativos, hace ineficiente para las cuestiones de desarrollo urbano, la espera y resoluciones muy particulares o reducidas en lo que resuelven frente al problema de urbanismo que es mucho más amplio y complejo.

\section{CONCLUSIONES}

\section{A. Acreditación de la hipótesis}

El presente estudio buscó analizar los problemas que generan las normas jurídicas en materia de desarrollo urbano en México. Al respecto, se planteó como hipótesis que la Constitución y demás normas tienen competencias incompatibles que propician la falta de coordinación entre los tres niveles de gobierno, ocasionando diversos problemas institucionales que afectan desde la planeación, ejecución y control en materia de desarrollo urbano. 
Se demostró que los problemas urbanos hoy en día no sólo provienen del aumento demográfico en las ciudades, sino que existe una gran dispersión urbana que genera problemas de pobreza, vivienda, movilidad, contaminación y altos costos particulares y también al erario público al elevarse el precio de los servicios públicos. Esta problemática, coincide con diversos estudios urbanos que tienen como fundamento una visión institucional. Por ejemplo, Abonce (2014) considera como paradigmas a resolverse los temas de peatonalidad; conectividad; diversidad de usos de suelo, clases sociales y tipos de vivienda; calidad de la arquitectura y diseño urbano; la preservación de patrones urbanos y arquitectónicos; la redensificación de determinados sectores estratégicos de la ciudad; transporte público eficiente; y la participación social en la construcción de la ciudad.

Por su parte Gutiérrez (2009, p. 61) señala que, debido a la influencia de los modelos de desarrollo social y económico, junto con el intenso proceso de elaboración de planes en todo el país, se ha provocado un retroceso en la concepción, desarrollo y consolidación de la planeación urbana. Además, Kunz (2014) señala como problemas fundamentales: la falta de fortaleza de las instituciones en materia de planeación urbana y propiedad; la capacidad técnica de los equipos responsables de la aplicación de los planes en la materia; y la falta de voluntad política o visiones distintas para la administración del sistema en su conjunto.

Acreditando con ello la existencia de problemas en materia urbana. En cuanto al aspecto jurídico, si bien no es la única variable responsable de esta situación, se puede inferir que si contribuye en esta problemática al señalar las siguientes situaciones o relaciones entre éstas:

a) La materia de desarrollo urbano debe aplicar diversas disciplinas científicas y una coordinación u homogenización en su ejecución para conseguir una política eficaz. Sin embargo, la Constitución nacional presenta una gran dispersión, respecto a la forma de dividir las competencias entre los niveles de gobierno; encontrándose materias estrictamente federales, otras concurrentes y otras municipales; además de existir otras materias y competencias correlativas o indirectas al urbanismo que las aplican autoridades diferentes. Lo cual complica la coordinación o jerarquía al permitirse a muchas autoridades seguir su propia competencia.

b) La Constitución federal inicialmente da una preeminencia a la Federación en materia de asentamientos humanos (fracción XXIX-C del artículo 73); pero otorga otras competencias en favor del municipio respecto de usos de suelo y relativas (artículo 115), lo cual confronta la materia de urbanismo.

c) Situación que se aprecia en el orden secundario. En materia federal, la Ley de Asentamientos Humanos divide las competencias entre los tres niveles de gobierno y crea como principales instrumentos en la materia los planes de desarrollo urbano. Esta jerarquía federal desciende a las leyes y planes estatales, así como al propio nivel municipal. Sin embargo, la problemática surge cuando los estados y municipios, por medio de otras materias y el artículo 115 constitucional para el caso municipal, no siguen dicha jerarquía y plasman en sus planes y programas sus propios intereses particulares con fundamento en dichas competencias (ejemplo claro se aprecia en las modificaciones constantes a las políticas de uso de suelo).

d) Los conflictos jurídicos se amplían en virtud de que, desde la Constitución y las leyes y reglamentos correspondientes, presentan una serie de lagunas o formas de interpretar que favorecen la aplicación unilateral de criterios y, por consiguiente, de políticas. Ejemplo de ellos se aprecia en quién debería ser la autoridad para evaluar los planes y, sobre todo, corregir los desvíos de los mismos.

e) Inclusive en la intensa actividad de la Suprema Corte de Justicia en esta materia se aprecia la complejidad y falta de resolución uniforme de estos problemas. Aunque se puede apreciar una ligera mayoría en favor de la Federación por medio de sus competencias de asentamientos humanos, sigue siendo una constante fallar a favor de municipios frente a los estados al citar el artículo 115 constitucional.

f) No es posible contabilizar los casos de omisión o inacción de las autoridades en esta materia. Es frecuente que diversas autoridades promuevan e intenten políticas en coordinación, y fracasen cuando las otras partes no cooperan aduciendo que tienen su propia competencia (ya sea por cuestiones técnicas o políticas). Ejemplo claro es en materia metropolitana en la cual no existe colaboración ni instrumentos puntuales que ayuden a resolver estas situaciones. 


\section{B. Propuesta legal y administrativa}

Si bien estos problemas se pudieran seguir resolviendo vía amparo o controversias constitucionales; lo cierto es que se ha demostrado que estos problemas rebasan dichas vías, además de considerar lo lento que es, frente a la rapidez y urgencia que se necesita en estas materias. Además, se constata que muchas jurisprudencias son "recientes" frente a las reformas y aun así las problemáticas anteriores continúan bajo otros aspectos técnicos. Por tanto, se proponen como principales reformas jurídicas y administrativas las siguientes:

a) Definir y puntualizar en la Constitución nacional, la jerarquía de la Federación, vía las competencias en materia de "asentamientos humanos", frente a las competencias municipales en materia urbana contenidas en el artículo 115 constitucional. El modelo urbano de "autonomía" municipal en esta materia claramente no ha podido frente al fenómeno de expansión urbana.

b) En las leyes y planes federales, contemplar varios modelos urbanos y territoriales, en atención a las características socioeconómicas propias de cada región; $y$, en la normativa estatal realizar el mismo ejercicio en relación a las diferencias entre sus municipios.

c) Dotar con autoridad y personalidad jurídica, a cuerpos colegiados de los tres niveles de gobierno; regionales; y gabinetes sectoriales en cada nivel de gobierno; para que exista la especialización en la materia de desarrollo urbano; los cuales sean no sólo los impulsores de una planeación coordinada, sino que exista autoridad efectiva en la evaluación, modificación y correcciones en la ejecución de la política urbana.

d) En los planes de desarrollo urbano, establecer competencias y responsabilidades específicas para las autoridades correspondientes, tanto para su aplicación como en su evaluación y seguimiento. e) En relación con los cambios de uso de suelo y disposiciones que afectan en forma fundamental el desarrollo urbano municipal; al no existir congruencia con los planes correspondientes (sin importar el nivel de gobierno del plan) o representar una política que por sus dimensiones refleje un cambio importante en la política urbana (densidades, alturas, afectación o cambio de grandes vías de comunicación, grandes afectación de territorio respecto a cambio de uso de suelo; etc.), contar con un dictamen o certificación de dichos cuerpos colegiados para verificar la pertinencia y congruencia de la petición de dichos cambios urbanos. Es importante recalcar que, en la integración de dichos organismos colegiados de gobierno, estén presentes entidades de gobierno especializadas en estos temas (institutos de planeación, del medio ambiente, etc.), así como participación ciudadana efectiva.

f) Establecer mecanismos ciudadanos alternos que no sólo den seguimiento a los planes de desarrollo urbano, sino que tengan competencia para revertir o anular aquellas autorizaciones gubernamentales que vayan en contra de lo estipulado en las normas y los planes de desarrollo urbano.

La finalidad de estas propuestas y reformas, tanto jurídicas como administrativas, consiste en reducir la problemática e incentivos negativos que existen hoy en día en el orden jurídico; y así iniciar un debate en torno a estas propuestas con la finalidad de buscar los mejores esquemas que permitan una mayor coordinación entre los tres niveles de gobierno, evitar la toma de decisiones unilaterales, seguir con mayor eficiencia la planeación y ejecución de las políticas urbanas; así como aumentar en forma eficiente la participación ciudadana. 


\section{BIBLIOGRAFÍA}

- Abonce Meza, Ramón (2014). Desarrollo Urbano, Conferencia Magistral en el Diplomado de Desarrollo Urbano: Querétaro, Instituto Municipal de Planeación, junio.

- Anchondo Paredes, Víctor Emilio (2010). "Métodos de Interpretación Jurídica": México, IIJ-UNAM [en línea]. Disponible en: www.juridicas.unam.mx. [Consultado: 26 de abril de 2012].

- Arráez Morella, et. al. (2006). "La Hermenéutica: una actividad interpretativa". Sapiens. Revista Universitaria de Investigación, vol. 7, núm. 2, diciembre 2006, pp. 171-181.

- Cárdenas Elorduy, Enrique (2012). Historia del Desarrollo y la Planeación, Urbanos en México: México, Asociación Mexicana de Urbanistas.

- Carrasco Monteagudo, Inmaculada y Castaño Martínez, Ma. Soledad (2012). "La Nueva Economía Institucional". ICE, Nuevas Corrientes de Pensamiento Económico, Madrid, marzo-abril, pp. 43-53.

- CIDOC-SHF (2012). Estado actual de la vivienda en México 2012: México, Centro de Investigación y Documentación de la Casa y Sociedad Hipotecaria Federal.

- CONAPO (2007): “Población en México" [en línea]. Disponible en http://www.conapo. gob.mx/. [Consultado: 15 de julio 2014].

- Crawford, S. y Ostrom E. (1995). "A Grammar of Institutions". American Political Science Review, 89 (3), pp. 582-600.

- Foladori, Guillermo y Humberto Tommasino (2000). "El concepto de desarrollo sustentable treinta años después". Desenvolvimento e Medio Ambiente, UFPR, n. 1, jan-jun, pp. 41-56.

- Guimarães, Roberto P. (1994). "El Desarrollo Sustentable: ¿Propuesta Alternativa o Retórica Neoliberal?". Revista Eure, Vol. XXI, No. 61, Santiago de Chile, diciembre, pp. 41-56.
- Gutiérrez Chaparro, Juan José (2009). "Planeación Urbana en México: Un análisis crítico sobre su proceso de evolución". Revista Asuntos Urbanos Internacionales, 19, Concepción, Chile, mayo, pp. 52-63.

- IMCO (2011). Viviendas para Desarrollar Ciudades. Índice de Competitividad en Materia de Vivienda 2011: México, Instituto Mexicano para la Competitividad.

- INFONAVIT (2010). Plan Financiero 20112015: México, Infonavit.

- ITDP (2012). Planes Integrales de Movilidad: Lineamientos para una movilidad urbana sustentable. México: ITDP, Embajada Británica en México, CentroEure.

- Kunz B., Ignacio (2014). Introducción a la Economía del Suelo: Conferencia en el Diplomado de Desarrollo Urbano, Querétaro, IMPLAN, julio.

- LÉLÉ, S.M. (1991). “Sustainable Development: a critical review". World Development, v. 19, n. 6, june, pp. 607-21.

- North, D.C. (1990). Institutions, Institutional Change and Economic Performance: Cambridge, University Press.

- OECD (2008). "Sustainable Development: Linking Economy, Society, environment" [en línea]. Disponible en http://www.oecd.org/ insights/41774475.pdf. [Consultado: 20 de julio 2014].

- SEDESOL (2009). “Diagnóstico del Programa Hábitat. México" [en línea]. Disponible en http://www.sedesol2009.sedesol.gob.mx/ archivos/802567/file/Diagnostico_Habitat. pdf. [Consultado: 08 de noviembre de 2013].

- Williamson, Oliver E. (2000). "The New Institutional Economics". Journal of Economic Literature, Vol. XXXVIII, september, pp. 595-613.

\section{Normativa citada}

- Código Municipal (11 de mayo del 2204). Gaceta Municipal y Periódico Oficial La Sombra de Arteaga: Municipio de Querétaro, México.

- Código Urbano (30 de junio de 2012). 
Periódico Oficial La Sombra de Arteaga: Estado de Querétaro, México.

- Constitución Política de los Estados Unidos Mexicanos (1917). Última reforma (15 de septiembre del 2017). Diario Oficial de la Federación: México.

- Ley General de Asentamientos Humanos (28 de noviembre de 2016). Diario Oficial de la Federación: México.

- Ley Orgánica Municipal del Estado de Querétaro (24 de mayo del 2001). Periódico Oficial La Sombra de Arteaga: Estado de Querétaro, México.

- Programa Nacional de Desarrollo Urbano 2014-2018 (30 de abril del 2014). Diario Oficial de la Federación: México.

Jurisprudencia citada

- Sentencia de Controversia Constitucional 81/2007 (17 de noviembre 2012). Suprema
Corte de Justicia de la Nación, promovida por el Municipio de San Blas, Estado de Nayarit. Diario Oficial de la Federación.

- Sentencia de Controversia Constitucional 94/2009 (julio de 2011). Suprema Corte de Justicia de la Nación, Municipio de San Pedro Garza García en contra del Estado de Nuevo León. Semanario Judicial de la Federación y su Gaceta, Novena Época, Pleno, Tomo XXXIV.

- SentenciasdeControversiasConstitucionales (11 de junio de 2013). Suprema Corte de Justicia de la Nación, Instituto de Vivienda del Estado de Quintana Roo. Semanario Judicial de la Federación, Décima Época, Pleno, Libro XXIII, Tomo 1, agosto. Y Controversia Constitucional 13/2011.

\section{ANEXO I}

\section{Guía para entrevistas}

1. ¿Qué cargo ostenta?

2. ¿Cuáles son sus competencias en materia urbana?

3. ¿Qué relación, políticas o programas tiene frente a un Plan de Desarrollo Urbano?

4. ¿Qué relación tiene entre el Plan de Desarrollo Urbano y el Plan de Gobierno?

5. ¿Tiene y participa en alguna instancia de evaluación y seguimiento de dichos planes?

6. ¿Existen mecanismos jurídicos para interpretar o corregir las desviaciones de dichos planes?

7. ¿En qué grado considera que se respeta puntualmente y sin cambios legales el Plan de Desarrollo Urbano?

8. ¿Con qué otras autoridades de su propio nivel

de gobierno necesitan coordinarse por ley en sus actividades?

9. ¿Cuáles son esas actividades?

10. ¿Con qué otras autoridades de otro nivel de gobierno necesitan coordinarse por ley en sus actividades?

11. ¿Cuáles son esas actividades?

12. ¿En qué actividades, que no son obligatorias, pudiera coordinarse con otras autoridades?

13. ¿Qué tipo de conflictos o tensiones jurídicas tiene con otras autoridades?

14. ¿Qué tipo de conflictos tiene frente al público?

15. ¿Qué litigios tiene vigente frente a otra autoridad o frente al público? 